\title{
A combined dynamic economic emission dispatch and time of use demand response mathematical modelling framework
}

\author{
N. I. Nwulua) and X. Xia \\ Department of Electrical, Electronics and Computer Engineering, University of Pretoria, \\ Hatfield 0002, South Africa
}

(Received 26 February 2015; accepted 7 August 2015; published online 19 August 2015)

In this paper, we integrate a Demand Response (DR) program into the multi-objective dynamic economic emission dispatch (DEED) optimization problem. The resulting optimization problem is termed DR-DEED. The DR program is a time based program known as the Time of Use DR program. The DR program has been developed using the customers' Price Elasticity Matrices, which models the customer behavior under different conditions. An interactive control strategy between utility and consumers is proposed for the combined DR-DEED model, which determines the optimal power to be generated by minimizing fuel, emissions, and DR costs and also the optimal price. The customer in light of the utility's optimal price minimizes its electricity cost and optimally schedules power consumption. Obtained results indicate that DR programs are mutually beneficial to utility and consumers alike and can bring about desired demand reduction in the power system. (C) 2015 AIP Publishing LLC.

[http://dx.doi.org/10.1063/1.4928875]

\section{NOMENCLATURE}

$a_{k}, b_{k}, c_{k}$ fuel cost coefficients of generator $k$

$B\left(d_{i}\right) \quad$ total customer benefit in time $i$ from the use of $d_{i} \mathrm{~kW}$ h of electrical energy

$B\left(d_{0 i}\right) \quad$ benefit at $d_{0 i}$

$B_{a} \quad$ energy consumption of load $a$ in each time slot (MW h)

$C_{k} \quad$ fuel cost of generator $k$

$d_{0} \quad$ initial demand

$D_{i} \quad$ total system demand at time $i$

$d_{0 i} \quad$ initial demand at time $i$

$d_{i}^{m} \quad$ final system load of class $m$ at time $i$

$d_{0 i}^{m} \quad$ initial load of class $m$ at time $i$

$D R_{k} \quad$ maximum ramp down rates of generator $k$

$e_{k}, f_{k}, g_{k} \quad$ emission cost coefficients of generator $k$

$E_{k} \quad$ emissions cost for generator $k$

$E(i, i) \quad$ self-elasticity

$E_{a} \quad$ end time slot for load $a$

$N_{g} \quad$ number of generators

$E L_{i} \quad$ total energy level of the participating customer at the last round

A maximum number of loads $a$, the industrial customer wants to schedule

$p_{i} \quad$ utility defined price/tariff for each time slot in South African Rands ZAR/kW h

$p_{0} \quad$ initial price

$p_{0 j} \quad$ initial price at time $j$

$P_{k, i} \quad$ power generated from generator $k$ at time $i$

${ }^{\text {a) }}$ Author to whom correspondence should be addressed. Electronic mail: nnamdi.nwulu@up.ac.za 
$P_{k, \text { max }} \quad$ maximum capacity of generator $k$

$P_{k, \text { min }} \quad$ minimum capacity of generator $k$

$S_{a} \quad$ start time slot for load $a$

$T \quad$ number of dispatch interval

$U R_{k} \quad$ maximum ramp up rates of generator $k$

$V_{i a} \quad$ status of load $a$ in time slot $i$

$Z_{a} \quad$ total number of time slots required for load $a$ to complete its task

$\Delta d \quad$ change in demand

$\Delta d_{i} \quad$ change in demand at time $i$

$\Delta p \quad$ change in price

$\Delta p_{j} \quad$ change in price at time $j$

\section{INTRODUCTION}

The dynamic economic emission dispatch (DEED) problem is a variant of the mathematical problem known as dynamic economic dispatch (DED), which is formulated to determine the optimal scheduling of the committed generating unit's output whilst supplying the load demand over a dispatch period at minimum operating cost and also satisfying ramp rate constraints among other constraints. ${ }^{1-4}$ A review of DED is provided in Ref. 5 and presents various mathematical formulations and solution methods that have been applied to solve the problem. Electric utilities or GENCOs are requested to reduce emission of gaseous pollutants including $\mathrm{SO}_{2}, \mathrm{NO}_{\mathrm{x}}, \mathrm{CO}$, and $\mathrm{CO}_{2}$ from fossil fuel fired thermal plants as they are hazardous to human health. This has given rise to the mathematical optimization problem known as emission dispatching. ${ }^{6,7}$

Emission dispatching can be incorporated into the DED formulation in three principal ways. The first is patterned after the DED problem with the objective as minimizing emissions in lieu of fuel costs and is widely referred to as pure dynamic economic dispatch (PDED). ${ }^{8}$ An alternative method and by far the most popular minimizes both fuel cost and emission simultaneously under load demand constraint, ramp rate constraint, and other constraints, resulting in a multi-objective optimization problem known as DEED. ${ }^{9,10}$ The final approach is to minimize the fuel cost alone and utilize emissions as a constraint, defining a limit for allowable emissions and is termed Emissions Constrained Dynamic Economic Dispatch (ECDED). ${ }^{11}$

This paper introduces a price based Demand Response (DR) program into the DEED problem. The DEED problem determines the optimal power generation schedule over a time interval whilst simultaneously minimizing fuel and emission costs. Adding the price based DR program seeks to minimize the DR cost and determine the optimal price using customers' price elasticity matrices (PEM) and load economic models. Usually, electric utilities solve the DEED with other associated tasks like unit commitment, ${ }^{13,30}$ and due to the increasing interest in renewable energy, utilities also solve DEED with the incorporation of renewable energy sources like wind and solar power. ${ }^{1432-38}$ In light of the advent of the smart grid and the need to convert load customers into active interacting participants who engage with the utility to reduce system demand, ${ }^{15,31}$ we introduce a combined DEED with DR under an interactive control strategy. This would lead to the mitigation of incidences of brownouts and blackouts caused by ever increasing customer demand, which is one of the principal benefits of $\mathrm{DR} .^{31}$ In the formulation presented in this work, the utility minimizes the generation and DR costs and determines the optimal hourly price. Based on the utility determined price, the customers seek to minimize their electricity costs and thus determine their optimal load schedule. This interaction between the utility and the customer continues until a stabilized price and a desired level of customer participation is reached so as to maintain an optimal and sustainable market of the DR program. The major contributions of this paper are: (i) Three forms of PEM's (for different classes of customer loads) are used to represent customer load adjustments to variations in prices. These PEM's are integrated into the DEED problem via the power balance constraint and an addition of a DR cost term into the DEED objective function. (ii) The resulting multi-objective problem is transformed into a single objective function using the weighting factor approach and 
determines the optimal price and energy levels. (iii) A customer scheduling model is introduced which determines the optimal schedule for the three classes of customer loads in light of the utility price and energy levels. (iii) An interactive control strategy is proposed for effective coordination between the utility and the customer side and obtaining mutually acceptable prices and energy levels. (iv) The effectiveness of the final proposed mathematical model framework is shown with two test DR-DEED system setups. The first system setup involves six generators and two aggregated industrial customers while the second system setup consists of ten generators and two aggregated industrial customers. (v) Results obtained from the two system setups indicate that DR-DEED leads to reduction in customer power demand and a corresponding decrease in system emissions when compared to conventional DEED. The rest of this paper is organized as follows: Section II introduces the DEED mathematical formulations; Section III introduces demand response programs and reviews the concept of PEM and load economic models in DR programs. Section IV details the combined interactive DR DEED mathematical model. Section V focuses on numerical simulations using the developed DR-DEED model and presents obtained results. The paper is concluded in Section VI.

\section{DEED PROBLEM FORMULATION}

In this work, the approach is used whereby the fuel and emission costs are simultaneously minimized under load demand constraints amidst other constraints. The mathematical representation is presented below: ${ }^{12}$

$$
\begin{aligned}
& \min \sum_{i=1}^{T} \sum_{k=1}^{N g} C_{k}\left(P_{k, i}\right), \\
& \min \sum_{i=1}^{T} \sum_{k=1}^{N g} E_{k}\left(P_{k, i}\right),
\end{aligned}
$$

with

$$
\begin{gathered}
C_{k}\left(P_{k, i}\right)=a_{k}+b_{k} P_{k, i}+c_{k} P_{k, i}^{2}, \\
E_{k}\left(P_{k, i}\right)=e_{k}+f_{k} P_{k, i}+g_{k} P_{k, i}^{2},
\end{gathered}
$$

subject to the following network constraints:

$$
\begin{gathered}
\sum_{k=1}^{N g} P_{k, i}=D_{i}+\operatorname{Loss}_{i}, \\
P_{k, \min } \leq P_{k, i} \leq P_{k, \max }, \\
-D R_{k} \leq P_{k, i+1}-P_{k, i} \leq U R_{k}, \\
\operatorname{Loss}_{i}=\sum_{k=1}^{N g} \sum_{j=1}^{N g} P_{k, i} B_{j, k} P_{j, i} .
\end{gathered}
$$

The following is a brief description of the constraints:

- The first constraint (5) ensures that at any time $i$, the total power generated equals the demand.

- The second constraint (6) ensures that the generator limits are not exceeded.

- The final constraint (7) ensures that the generator ramp rate limits are not violated.

The multi-objective optimization can be transformed into a single objective function using a weighting factor $w$ subject to the same constraints (5)-(7). 


$$
\min \left[w \sum_{i=1}^{T} \sum_{k=1}^{N g} C_{k}\left(P_{k, i}\right)+(1-w) \sum_{i=1}^{T} \sum_{k=1}^{N g} E_{k}\left(P_{k, i}\right)\right] .
$$

\section{PRICE BASED DR PROGRAMS}

In general, demand response programs are used to induce lower electricity use at times of high wholesale market prices or when system reliability is jeopardized. ${ }^{16}$ In cases where the utility is a monopoly, an advantage of demand response programs is an improvement in power system efficiency and power system reliability. There is also the advantage of a reduction in operating costs and emissions. In deregulated markets, the same advantages in monopolistic markets apply. Furthermore, there is the advantage of reduced wholesale market prices. ${ }^{17,18}$ In incentive based DR programs, incentives are simply offered to consumers to reduce or curtail their electricity use when the power system is stressed. The incentives can be in the form of rebates or lower electricity tariffs. ${ }^{19,20}$ In price based DR programs, there is a time variation of electricity tariffs. The price based DR program used in this work is the time of use DR (TOUDR) program. For this kind of program, the price of elasticity is calculated for peak, off-peak, and standard times based on the energy cost in each time period. The aim is to encourage consumers to curtail their energy use to take advantage of favourable prices. ${ }^{21,22}$

The load economic profile for these kinds of programs is given below: ${ }^{23}$

The customers profit is given as

$$
S_{i}=B\left(d_{i}\right)-p_{i} d_{i}
$$

To maximize customers' profit, $\partial S_{i} / \partial d_{i}$ should be equal to zero; therefore

$$
\frac{\partial B\left(d_{i}\right)}{\partial d_{i}}=p_{i} .
$$

The most common benefit function is the quadratic benefit function defined $\mathrm{as}^{23}$

$$
\begin{gathered}
B\left(d_{i}\right)=B\left(d_{0 i}\right)+p_{0 i}\left(d_{i}-d_{0 i}\right)\left[1+\frac{d_{i}-d_{0 i}}{2 E(i, i) \cdot d_{0 i}}\right], \\
\frac{\partial B\left(d_{i}\right)}{\partial d_{i}}=p_{0 i}\left[1+\frac{d_{i}-d_{0 i}}{E(i, i) \cdot d_{0 i}}\right] .
\end{gathered}
$$

Equating (11) and (13) we obtain that

$$
d_{i}=d_{0 i}\left[1+E(i, i) \frac{p_{i}-p_{0 i}}{p_{0 i}}\right] .
$$

Similarly, for the multiperiod elastic loads, it is assumed that demand rescheduling occurs. Thus, the demand at time $i$ is a function of prices at times $i=1,2 \ldots T$. In this work, we assume $T=24$ and the cross elasticity is given as $E(i, j)=\frac{\Delta d_{i} / d_{0 i}}{\Delta p_{j} / p_{0 j}}$.

Working with the linearity assumption that $\frac{\Delta d_{i}}{\Delta p_{j}}$ is constant for $i, j=1,2,3, \ldots .24$, the following relationship is obtained between price and demand:

$$
d_{i}=d_{0 i}\left[1+\sum_{\substack{j=1 \\ j \neq i}}^{24} E(i, j) \frac{p_{j}-p_{0 j}}{p_{0 j}}\right] .
$$

Combining the single period (14) and multiperiod (15), we obtain 


$$
\begin{aligned}
& d_{i}=d_{0 i}\left[1+E(i, i) \frac{p_{i}-p_{0 i}}{p_{0 i}}+\sum_{\substack{j=1 \\
j \neq i}}^{24} E(i, j) \frac{p_{j}-p_{0 j}}{p_{0 j}}\right], \\
& E_{\text {inflexible }}=\left[\begin{array}{ccccccc}
E(1,1) & E(1,2) & 0 & 0 & 0 & 0 & 0 \\
E(2,1) & E(2,2) & 0 & 0 & 0 & 0 & 0 \\
0 & 0 & E(3,3) & E(3, j) & 0 & 0 & 0 \\
0 & 0 & E(i, 3) & E(i, j) & E(i, 22) & 0 & 0 \\
0 & 0 & 0 & E(22, j) & E(22,22) & 0 & 0 \\
0 & 0 & 0 & 0 & E(23,22) & E(23,23) & E(23,24) \\
0 & 0 & 0 & 0 & 0 & E(24,23) & E(24,24)
\end{array}\right], \\
& E_{\text {flexible }}=\left[\begin{array}{ccccccc}
E(1,1) & 0 & 0 & 0 & 0 & 0 & 0 \\
E(2,1) & E(2,2) & 0 & 0 & 0 & 0 & 0 \\
E(3,1) & E(3,2) & E(3,3) & 0 & 0 & 0 & 0 \\
E(4,1) & E(4,2) & E(4,3) & E(4, j) & 0 & 0 & 0 \\
E(5,1) & E(5,2) & E(5,3) & E(5, j) & 0 & 0 & 0 \\
0 & E(6,2) & E(6,3) & E(6, j) & 0 & 0 & 0 \\
0 & 0 & E(7,3) & E(7, j) & 0 & 0 & 0 \\
0 & 0 & 0 & E(8, j) & 0 & 0 & 0 \\
0 & 0 & 0 & 0 & E(19,22) & E(19,23) & 0 \\
0 & 0 & 0 & 0 & E(20,22) & E(20,23) & E(20,24) \\
0 & 0 & 0 & 0 & E(21,22) & E(21,23) & E(21,24) \\
0 & 0 & 0 & 0 & E(22,22) & E(22,23) & E(22,24) \\
0 & 0 & 0 & 0 & 0 & E(23,23) & E(23,24) \\
0 & 0 & 0 & 0 & 0 & 0 & E(24,24)
\end{array}\right] \text {, } \\
& E_{\text {night-time }}=\left[\begin{array}{ccccccc}
E(1,1) & E(1,2) & \ldots & E(1, j) & \ldots & E(1,23) & E(1,24) \\
E(1,2) . & E(2,2) & \ldots & E(2, j) & \ldots & E(2,23) & E(2,24) \\
0 & 0 & E(3,3) & 0 & 0 & 0 & 0 \\
0 & 0 & 0 & E(i, j) & 0 & 0 & 0 \\
0 & 0 & 0 & 0 & E(22,22) & 0 & 0 \\
E(1,23) & E(2,23) & \ldots & E(i, 23) & \ldots & E(23,23) & E(23,24) \\
E(1,24) & E(2,24) & \ldots & E(i, 24) & \ldots & E(23,24) & E(24,24)
\end{array}\right]
\end{aligned}
$$

\section{COMBINED INTERACTIVE DEMAND RESPONSE-DYNAMIC ECONOMIC EMISSIONS ECONOMIC DISPATCH (DR-DEED)}

In this work, the DR target loads fall into three different classes. ${ }^{24}$ The load classes are: inflexible loads, flexible loads, and night-time loads. For instance, the inflexible loads are the customer loads that must be switched on. Customers would not curtail these loads to participate in demand response programs as they impact heavily on the benefit of customers. For residential customers, examples of these kinds of loads are cookers, stoves, refrigerators, and heating systems. Depending on the industry, some loads are also inflexible for industrial customers like industrial motors for some critical processes. The other loads are loads that customers are willing to curtail. However, customers have varying load responses to price increases, hence different degrees of flexibility. Flexible loads are loads that customers are completely flexible about. 
They can readily adjust these loads to price variations. Examples of such kinds of loads for residential customers are vacuum cleaners, dishwashers, and water purifiers/boilers. Industrial examples of this kind of load are industrial pumps. Finally, night-time loads are loads that the customer can schedule to hours with the lowest electricity prices, e.g., late in the night and very early hours of the morning. Examples of such kinds of loads for residential customers are washing machines, electric hot water heaters, and tumble dryers. For industrial customers, these can include furnaces. It is assumed that there is a mix of these classes of loads in the power system with the total power system load, a summation of the three different classes. It is further assumed that the utility has an estimate of each class of load and each load class has a different PEM. The PEMs are obtained through a historical analysis of customers' demand response to increases or decreases (deviations) in the price of electricity. Each load class has a different PEM, i.e., a $24 \times 24$ square matrix. The difference between the PEM of each load class is the position of the non-zero elements in the matrix. Equations (17)-(19) shows sample PEM structure for inflexible, flexible, and night-time loads, respectively.

Since there are three types of load classes $m ; m=1,2,3$, the total system load is a summation of the three load classes. We define $d_{0 i}^{m}$ as the initial load of class $m$ at time $i$. The total initial system load $d_{0 i}=\sum_{m=1}^{3} d_{0 i}^{m}$ and $d_{i}^{m}$ is defined as the final system load of class $m$ at time $i$. The total final system load $d_{i}=\sum_{m=1}^{3} d_{i}^{m}$. The cost of the DR program to the utility at time $i$ can therefore be defined as

$$
\operatorname{cost} D R_{i}=p_{0 i} \cdot d_{0 i}-p_{i} \cdot d_{i} .
$$

Thus, the weighted single objective DR-DEED mathematical formulation from the utility perspective can be given as

$$
\min \left[w\left[\sum_{i=1}^{T} \sum_{k=1}^{N g} C_{k}\left(P_{k, i}\right)+\sum_{i=1}^{T} \operatorname{cost} D R_{i}\right]+(1-w) \sum_{i=1}^{T} \sum_{k=1}^{N g} E_{k}\left(P_{k, i}\right)\right],
$$

subject to the following network constraints:

$$
\begin{aligned}
& \sum_{k=1}^{N g} P_{k, i}=d_{i}+\operatorname{Loss}_{i}, \\
& P_{k, \text { min }} \leq P_{k, i} \leq P_{k, \max }, \\
& -D R_{k} \leq P_{k, i+1}-P_{k, i} \leq U R_{k}, \\
& d_{i}^{m}=d_{0 i}^{m}\left[1+E_{m}(i, i) \frac{p_{i}-p_{0 i}}{p_{0 i}}+\sum_{\substack{j=1 \\
j \neq i}}^{24} E_{m}(i, j) \frac{p_{j}-p_{0 j}}{p_{0 j}}\right], \\
& \operatorname{Loss}_{i}=\sum_{k=1}^{N g} \sum_{j=1}^{N g} P_{k, i} B_{j, k} P_{j, i} .
\end{aligned}
$$

An interactive control strategy is used in this work. The reason behind an interactive control strategy is to obtain a final optimal price and energy levels satisfactory to both the utility and customers. Thus, the utility initially determines the optimal price $\left(p_{i}\right)$ and suggested energy level $\left(d_{i}\right)$ using Eqs. (20)-(26). The customers respond by scheduling their appliances and loads in light of the provided utility price. The responding customers' energy levels are sent back to the utility and the utility revises the PEMs. The utility again determines the price in light of the responding customers' energy levels and revised PEMs. This process is repeated until convergence is achieved. Figure 1 shows the complete flow chart for the proposed interactive control 


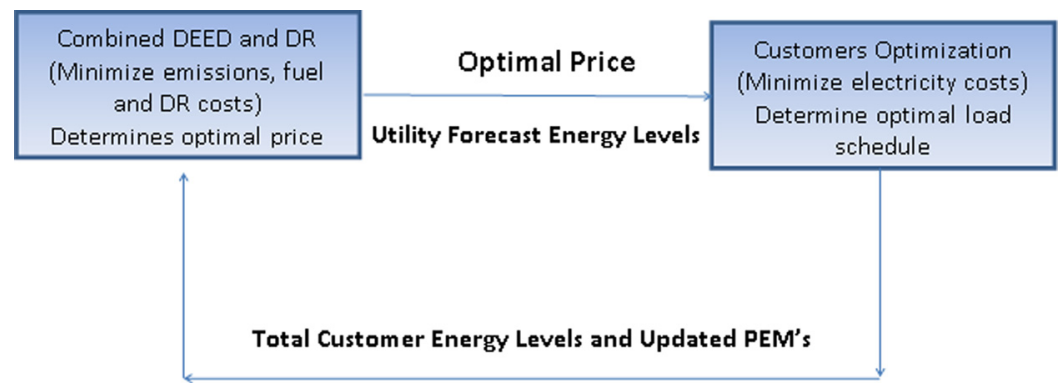

FIG. 1. Flowchart of the interactive DR-DEED program.

strategy. The intention of this interactive design of the DR program is to seek an optimal price signal and a desired level of market participation of the DR program.

\section{A. Customer side objective function and constraints}

The participating customer first needs to classify his loads into the three available load classes: flexible, inflexible, and night-time loads. The customer's optimization model has an objective function that minimizes the electricity bill/costs of all three kinds of loads. In this work, two groups of industrial customers are assumed. In the model formulation given below, $i$ represents time slot and $a$ represents the loads of the industrial customer. The decision variable is binary $V_{i a}$, which is either 1 or 0 and represents if the loads $a$ is switched on or off in time slot $i$. The consumers are assumed to be acting rationally and seek to minimize electricity costs of all loads, devices, machines, or appliances. We assume a scheduling interval of $1 \mathrm{~h}$; thus, in 1 day, there will be 24 time slots. The objective function and constraints are represented mathematically as

$$
\min \sum_{i=1}^{24} \sum_{a=1}^{A} B_{a} V_{i a} p_{i}
$$

subject to

$$
\begin{gathered}
\sum_{S_{a}}^{E_{a}} V_{i a}=Z_{a}, \\
\sum_{a=1}^{A} B_{a} V_{i a} \leq E L_{i} .
\end{gathered}
$$

The following is a brief explanation of the constraints:

- Constraint (28) ensures that there are sufficient time slots for a load, device, or machine to complete its tasks. This is also the constraint that handles the flexibility of the appliance/load. For instance, let us assume two time slots are required for an appliance to complete a task, i.e., $Z_{a}=2$. If the customer is flexible about the appliance, i.e., the appliance must not run at specific time slots, the difference between the start time slot $S_{a}$ and end time slot $E_{a}$ would be greater than $Z_{a}$. If the customer is however inflexible about the appliance, the difference between start time slot $S_{a}$ and end time slot $E_{a}$ would be exactly $Z_{a}$. For night-time loads, both start time slot $S_{a}$ and end time slot $E_{a}$ would be either in the early hours of the morning or late at night.

- The final constraint (29) ensures that the customer's new energy level does not exceed the energy level of the last round. For the initial optimization, it is the maximal estimated energy level for that customer. This ensures that there is actually relief in the power system. 


\section{NUMERICAL SIMULATIONS, OBTAINED RESULTS, AND DISCUSSIONS}

In this section, we present the parameters and results of the combined interactive DRDEED optimization model both at the utility side and at the customer side. The proposed mathematical optimization models are tested on two example test systems. The first example test system is a six unit test system and the second is a ten unit test system. In both numerical simulations, the default weighting factor $w=0.5$ and the following condition is required to be satisfied:

$$
w+(1-w)=1 .
$$

This is done to give equal preference to both objective functions and not to minimize/maximize an objective function at the expense of the other. ${ }^{6,12,26,29,31}$ Investigations are carried out to determine the effect of varying one weighting factor at the expense of the other and its impact on the power system parameters.

\section{A. Test system 1}

Test system 1 consists of six unit generators at the supply side and two aggregated industrial customers at the customer side. At the utility side, the goal is to obtain the optimal price $p_{i}$ and forecast demand $d_{i}$, while at the customer side, the major aim is to obtain the optimal customer schedule in view of the utility determined optimal price and forecast demand.

The fuel cost coefficients and the emission cost coefficients modified are obtained from Ref. 12 and shown in Table $\mathrm{X}$ in the Appendix. The initial electricity tariff values are obtained from Eskom's (the South African utility) Tariff book $^{25}$ and shown in Table XI in the Appendix. The total initial demand is also shown in Table XI. The TOU periods are assumed to be off-peak (23:00-04:00) hours, standard (05:00-06:00, 11:00-17:00, and 21:00-22:00) hours, and peak (07:00-10:00 and 18:00-20:00) hours. ${ }^{25}$ The assumed TOU elasticity values obtained from Ref. 24 are given in Table I. The transmission loss formula coefficients for the six unit test system are given in the below equation:

$$
B=10^{-4} \times\left[\begin{array}{cccccc}
0.420 & 0.051 & 0.045 & 0.057 & 0.078 & 0.066 \\
0.051 & 0.180 & 0.039 & 0.048 & 0.045 & 0.060 \\
0.045 & 0.039 & 0.195 & 0.051 & 0.072 & 0.057 \\
0.057 & 0.048 & 0.051 & 0.213 & 0.090 & 0.075 \\
0.078 & 0.045 & 0.072 & 0.090 & 0.207 & 0.096 \\
0.066 & 0.060 & 0.057 & 0.075 & 0.096 & 0.255
\end{array}\right] \text { per MW. }
$$

Most logical customers are always on the lookout for ways or measures to use energy efficiently and do so at minimal cost. ${ }^{26,27}$ In this work, the goal of the customer is to minimize their electricity bill/costs and optimally schedule their appliance and hence their energy plan in light of the provided utility optimal price. To verify the mathematical formulations for the customer side (Eqs. (27)-(29)), two aggregated industrial consumers are assumed. Both aggregated industrial customer groups consist of 20 and 15 identical customers, respectively, and there is a regulator that can schedule these loads. The underlying principles can easily be extended to

TABLE I. TOU self and cross elasticity.

\begin{tabular}{lccc}
\hline \hline & Peak & Off-peak & Standard \\
\hline Peak & -0.1 & 0.016 & 0.012 \\
Off-peak & 0.016 & -0.1 & 0.01 \\
Standard & 0.012 & 0.01 & -0.1 \\
\hline \hline
\end{tabular}


TABLE II. Load data for customer in the first group.

\begin{tabular}{|c|c|c|c|c|}
\hline & $B_{a(\mathrm{MW} \mathrm{h})}$ & $S_{a}(\mathrm{~h})$ & $E_{a}(\mathrm{~h})$ & $Z_{a}(\mathrm{~h})$ \\
\hline \multicolumn{5}{|l|}{ Flexible } \\
\hline Load 1 & 5 & 1 & 24 & 12 \\
\hline Load 2 & 4 & 1 & 24 & 12 \\
\hline \multicolumn{5}{|l|}{ Inflexible } \\
\hline Load 3 & 15 & 1 & 24 & 24 \\
\hline Load 4 & 10 & 1 & 24 & 24 \\
\hline \multicolumn{5}{|l|}{ Night-time } \\
\hline Load 5 & 5 & 1 and 21 & 6 and 24 & 5 \\
\hline Load 6 & 1.5 & 1 and 21 & 6 and 24 & 4 \\
\hline
\end{tabular}

residential or other kinds of customers. The customer just has to identify the loads that can be grouped under flexible, night-time, and inflexible. For the sake of simplicity, it is further assumed that the customer classification does not change and each customer has six loads. Tables II and III show the load data for an individual customer in the two groups.

The optimization models are built and solved using the Advanced Interactive Multidimensional Modelling System (AIMMS) ${ }^{28}$ AIMMS is an Algebraic Modelling Language (AML) used for solving optimization and scheduling type mathematical problems. The major advantage of using AIMMS is the similarity of the software's syntax to the mathematical representation of optimization problems. The software supports the solution of a large number of optimization problem types and allows for an easy reproduction of their results without a violation of any of the constraints. The particular solver used is the CPLEX 12.6 solver, and all the constraints of the mathematical model are satisfied. After the first utility optimization (Eqs. (20)-(26)) and the corresponding customer side optimization (Eqs. (27)-(29)), the customers return their energy consumption to the utility. The utility revises the PEMs and again performs optimization. This interactive control process continues until convergence is reached. In this work, after the third round of interactive control, convergence was achieved.

In Figure 2, the load profiles at the various stages of the interactive control process are shown. It shows that there is a reduction in peak demand and also a shifting of load from peak periods $(07: 00 \mathrm{~h}-08: 00 \mathrm{~h}$ and $18: 00 \mathrm{~h}-20: 00 \mathrm{~h})$ to the standard and off peak periods. This is obvious from the difference between the initial load and the second customer load which is the load at which convergence was reached during the interactive process. Figure 3 shows the TOU price movements over a $24 \mathrm{~h}$ scheduling horizon during different stages of the interactive control process. It is obvious that there is a price reduction in standard and off peak periods and an increase in peak periods. The increase and decrease in prices influence the end user's energy consumption and bring about peak load reduction and load shifting. Figure 4 shows the initial system

TABLE III. Load data for customer in the second group.

\begin{tabular}{|c|c|c|c|c|}
\hline & $B_{a(\mathrm{MW} \mathrm{h})}$ & $S_{a}(\mathrm{~h})$ & $E_{a}(\mathrm{~h})$ & $Z_{a}(\mathrm{~h})$ \\
\hline \multicolumn{5}{|l|}{ Flexible } \\
\hline Load 1 & 15.7 & 1 & 24 & 12 \\
\hline Load 2 & 5.3 & 1 & 24 & 12 \\
\hline Load 3 & 14 & 1 & 20 & 11 \\
\hline \multicolumn{5}{|l|}{ Inflexible } \\
\hline Load 4 & 15 & 1 & 24 & 24 \\
\hline \multicolumn{5}{|l|}{ Night-time } \\
\hline Load 5 & 5 & 1 and 21 & 6 and 24 & 5 \\
\hline Load 6 & 5 & 1 and 21 & 6 and 24 & 4 \\
\hline
\end{tabular}




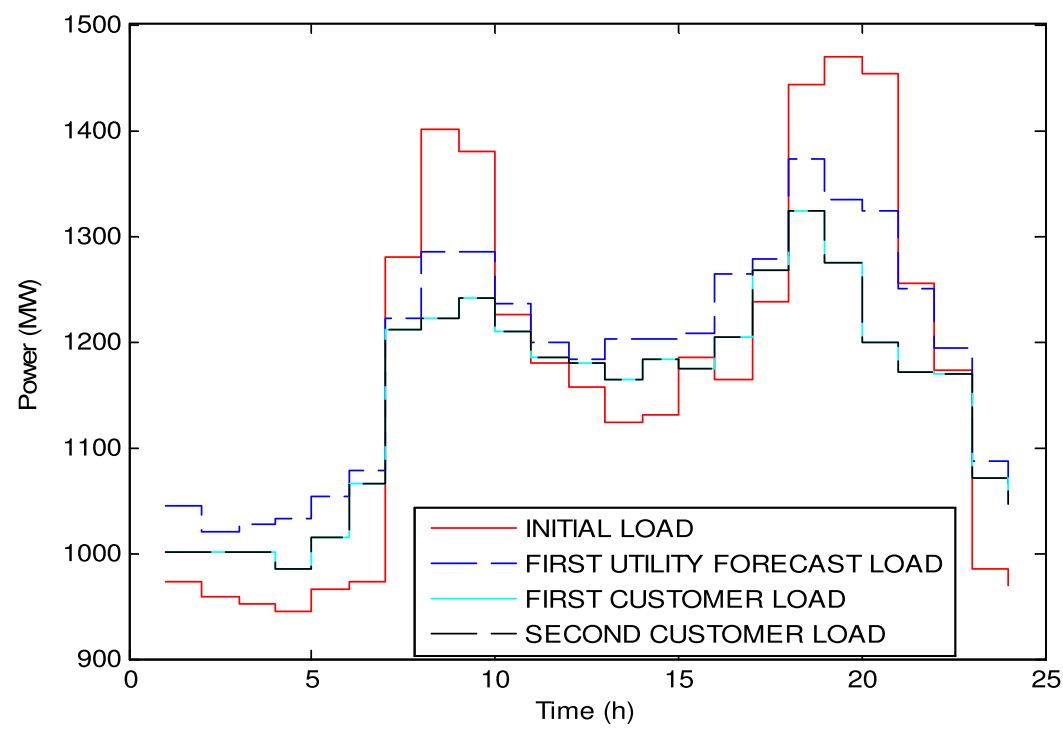

FIG. 2. Load profiles at different stages of interactive control.

load and the optimal final converged load. These two load profiles are extracted from Figure 2 and show the load profile at the beginning of the interactive control process and the optimal load profile at the end of the interactive control process. The essence is to enable a clearer view of the magnitude of load reduction and shifting. Similarly, Figure 5 is an extract from Figure 3 and shows the initial price and optimal final utility price obtained via the interactive control process. The magnitude of price movements (increase and decrease) is clearly visible.

Figures 6-11 show the optimal power generated for all six generators under initial system load (normal DEED) and optimal converged load (TOU-DEED). From these figures, we observe that due to the effect of load profile changes (see Figure 2), the power generated from the different generators reduces in peak periods and increases in standard and off peak periods. This is because the total generated power must always satisfy total demand (power balance

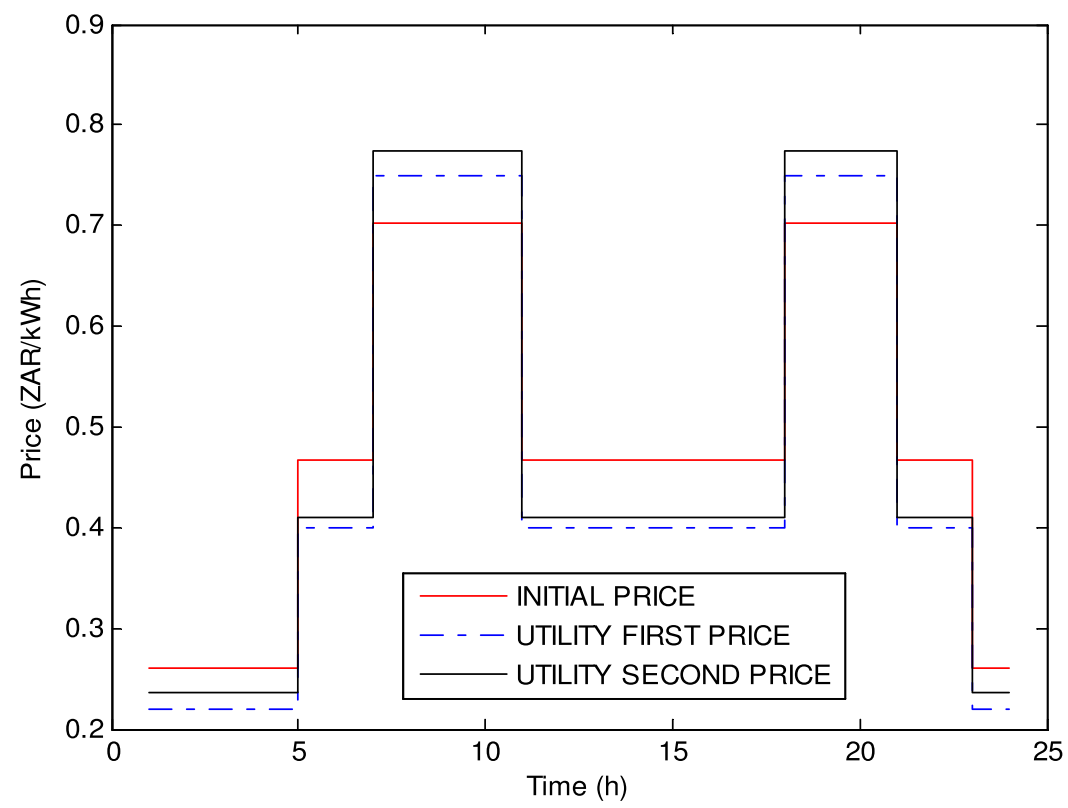

FIG. 3. Utility determined price at different stages of interactive control. 


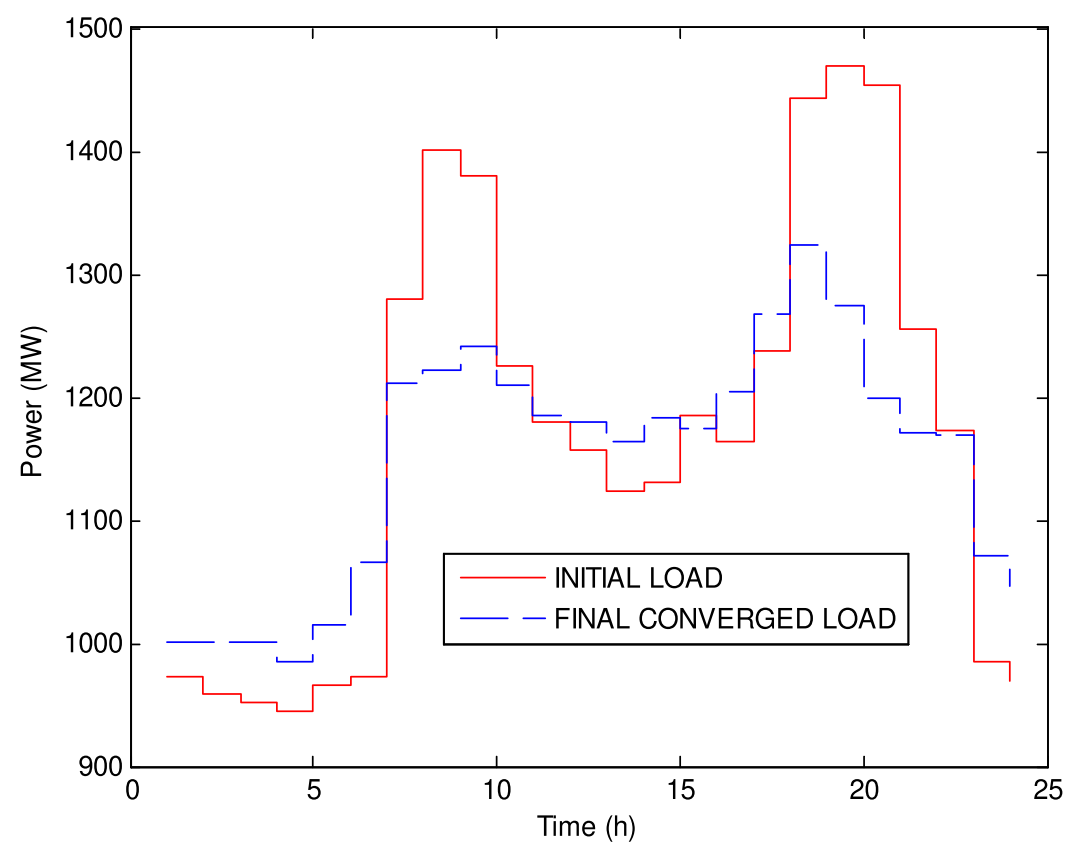

FIG. 4. Initial load and final converged load.

constraint). Table IV shows the results of varying the weighting factors on the fuel costs, emissions, and power loss under both DEED and DR-DEED for the first test system. The aim is to show the effect of a trade-off between conflicting objectives on system parameters.

The final customer optimal scheduling solution is shown in Tables V and VI for customers in the first and second groups, respectively.

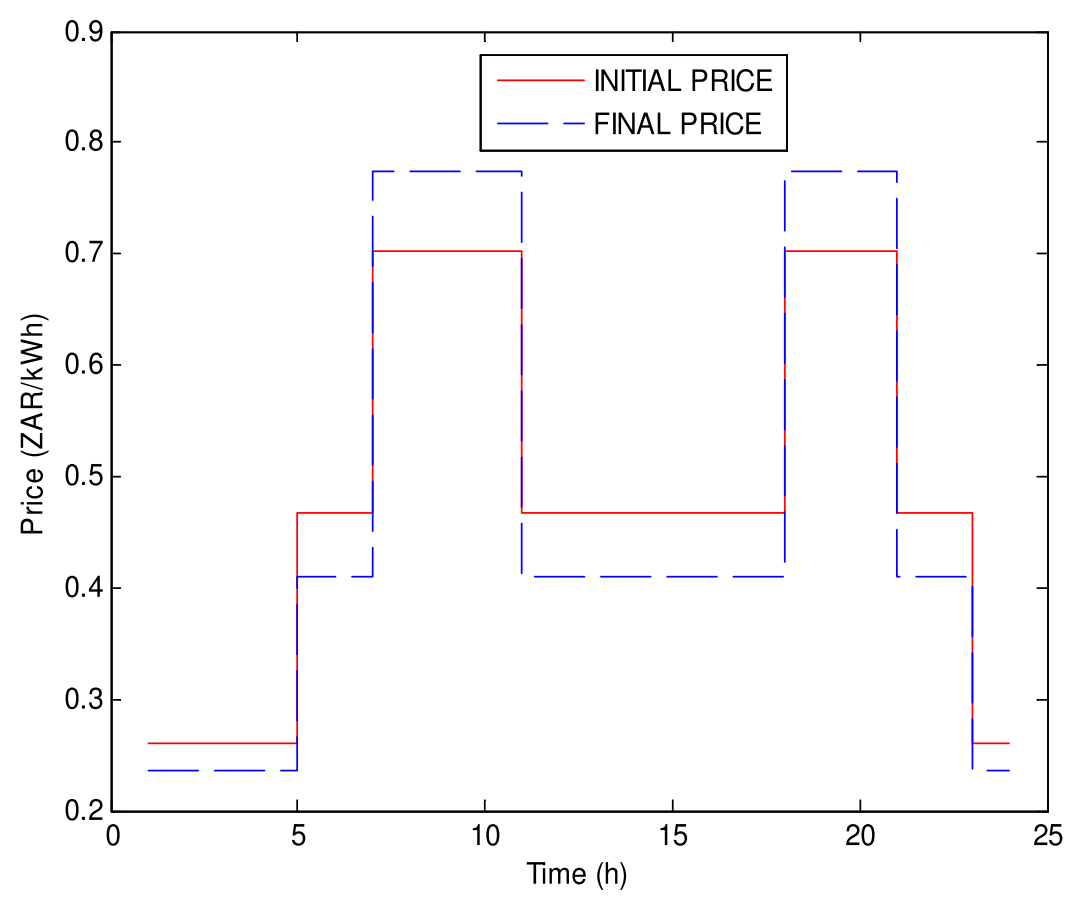

FIG. 5. Initial price and final price. 


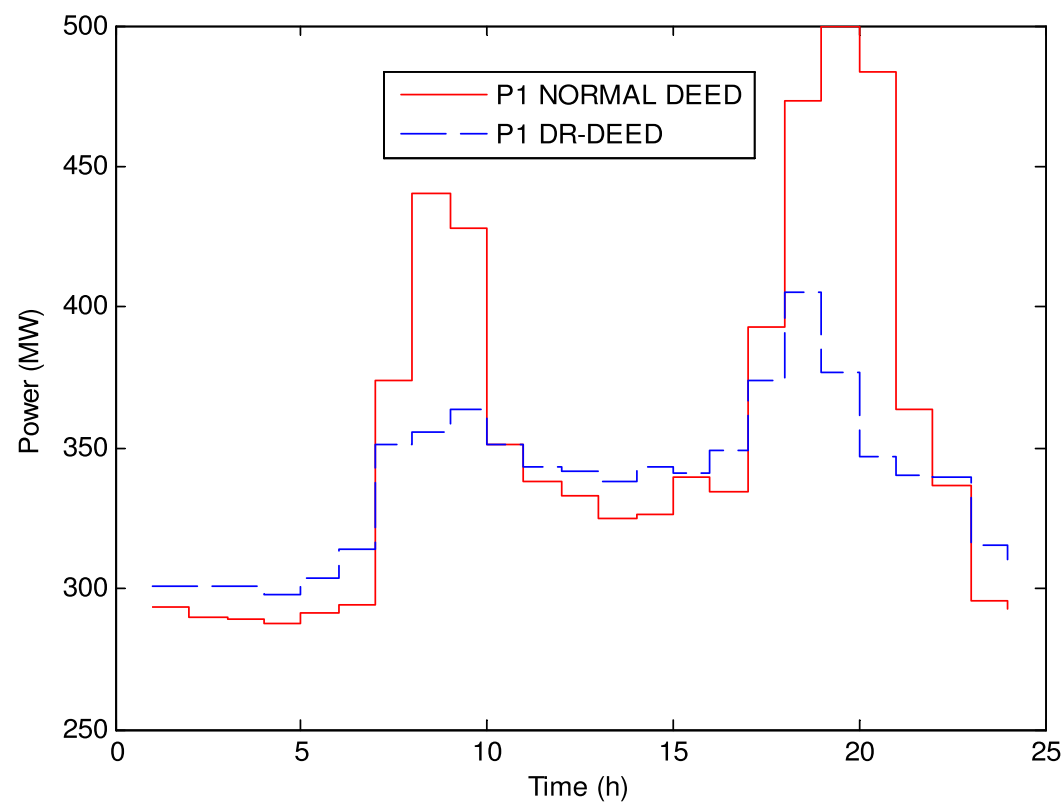

FIG. 6. Generation output of unit 1.

\section{B. Test system 2}

Test system 2 consists of ten unit generators at the supply side and two aggregated industrial customers at the customer side. Similar to the first example test system, we verify the mathematical formulations at both the utility and the customer side.

The fuel cost coefficients and the emission cost coefficients modified are obtained from Ref. 6 and shown in Table XII in the Appendix. The initial electricity tariff values are similarly obtained from Eskom's (the South African utility) Tariff book ${ }^{25}$ and shown in Table XIII in the Appendix. The total initial demand is also shown in Table XIII. The TOU periods and elasticity values are as assumed in the first example test system given in Table I. The transmission loss formula coefficients for the ten unit test system are given as follows:

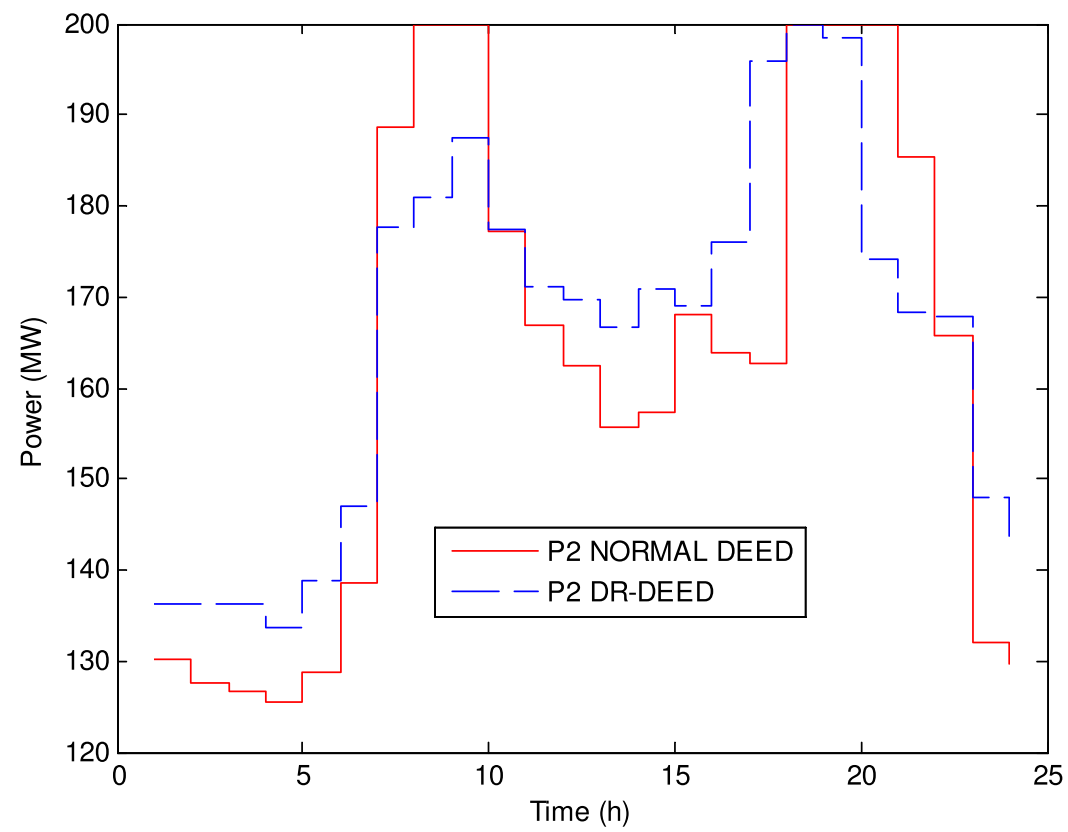

FIG. 7. Generation output of unit 2. 


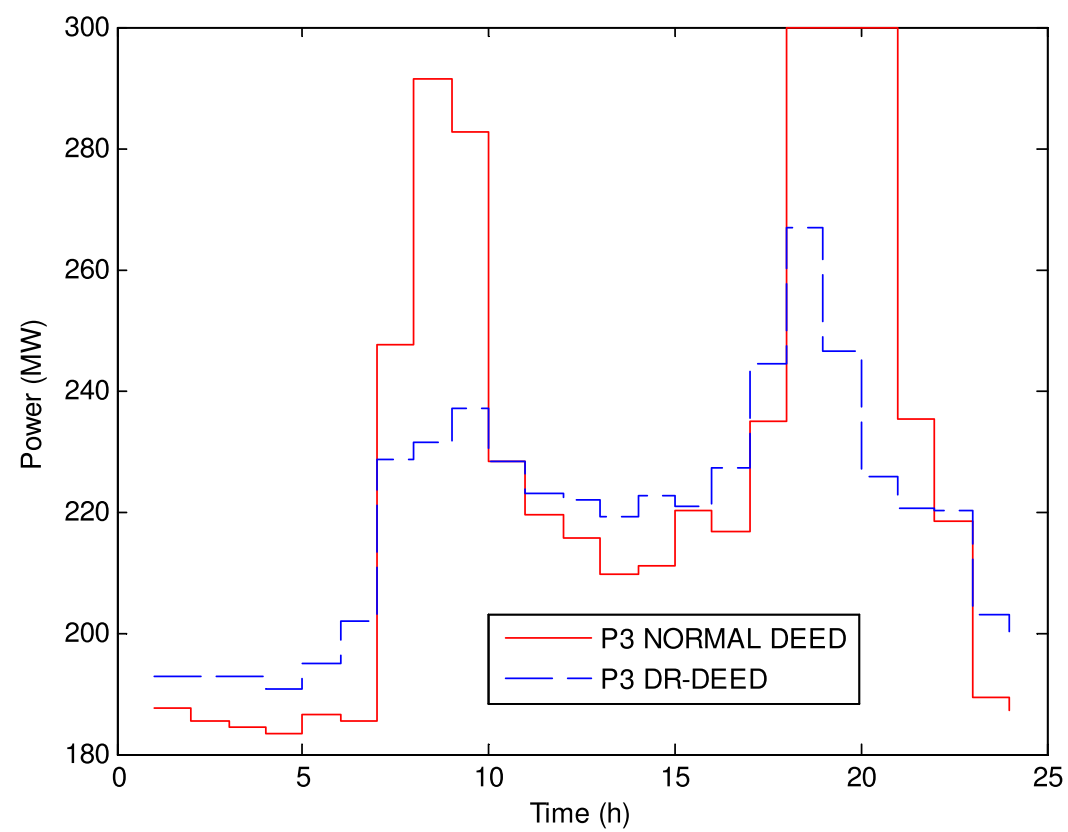

FIG. 8. Generation output of unit 3.

$B=10^{-5} \times\left[\begin{array}{cccccccccc}4.9 & 1.4 & 1.5 & 1.5 & 1.6 & 1.7 & 1.7 & 1.8 & 1.9 & 2.0 \\ 1.4 & 4.5 & 1.6 & 1.6 & 1.7 & 1.5 & 1.5 & 1.6 & 1.8 & 1.8 \\ 1.5 & 1.6 & 3.9 & 1.0 & 1.2 & 1.2 & 1.4 & 1.4 & 1.6 & 1.6 \\ 1.5 & 1.6 & 1.0 & 4.0 & 1.4 & 1.0 & 1.1 & 1.2 & 1.4 & 1.5 \\ 1.6 & 1.7 & 1.2 & 1.4 & 3.5 & 1.1 & 1.3 & 1.3 & 1.5 & 1.6 \\ 1.7 & 1.5 & 1.2 & 1.0 & 1.1 & 3.6 & 1.3 & 1.2 & 1.4 & 1.5 \\ 1.7 & 1.5 & 1.4 & 1.1 & 1.3 & 1.2 & 3.8 & 1.6 & 1.6 & 1.8 \\ 1.8 & 1.6 & 1.4 & 1.2 & 1.3 & 1.2 & 1.6 & 4.0 & 1.5 & 1.6 \\ 1.9 & 1.8 & 1.6 & 1.4 & 1.5 & 1.4 & 1.6 & 1.5 & 4.2 & 1.9 \\ 2.0 & 1.8 & 1.6 & 1.5 & 1.6 & 1.5 & 1.8 & 1.6 & 1.9 & 4.4\end{array}\right]$ per MW.

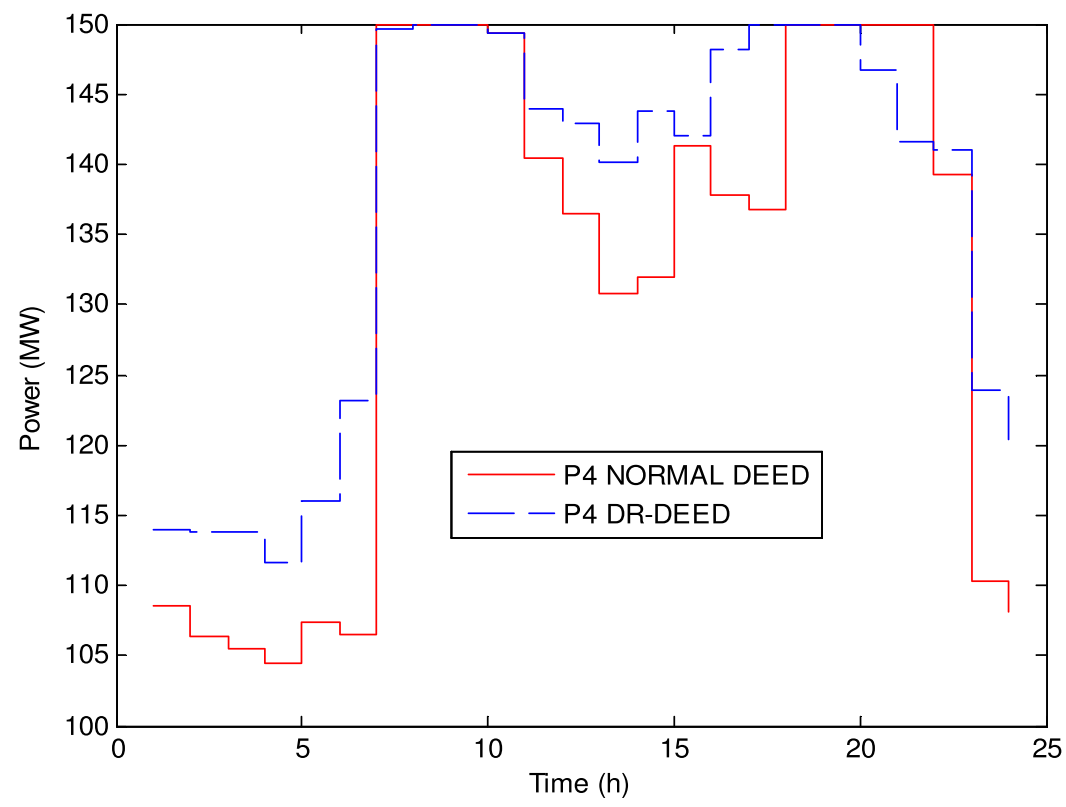

FIG. 9. Generation output of unit 4. 


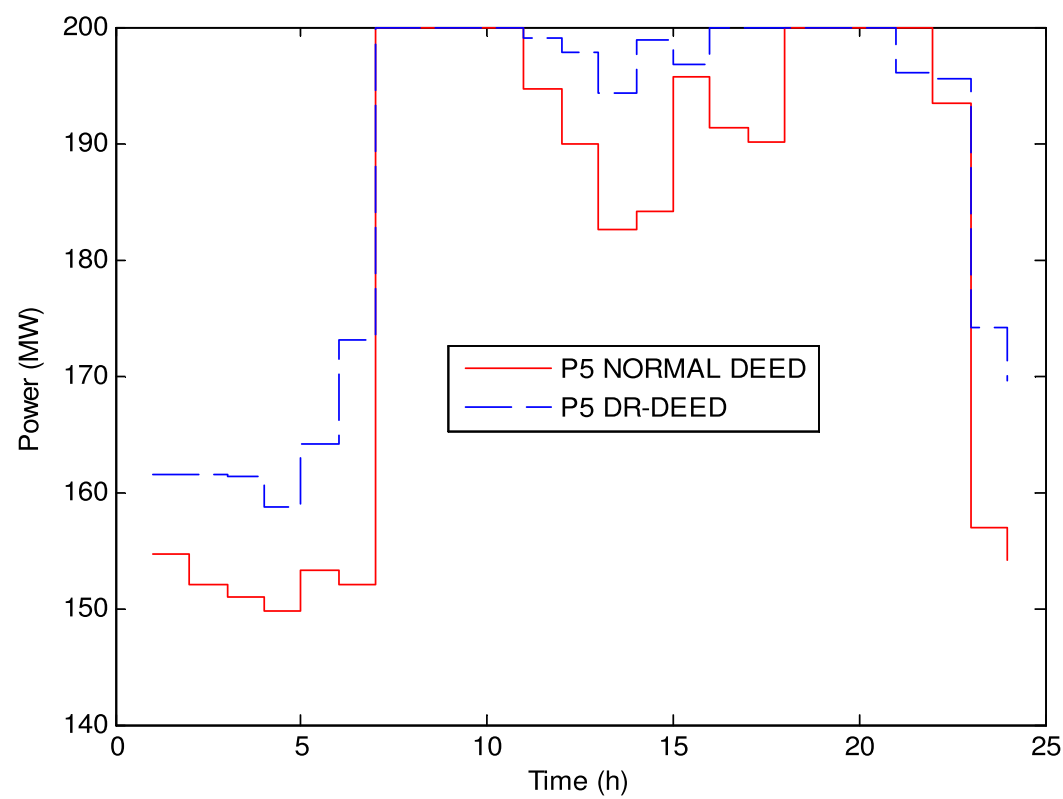

FIG. 10. Generation output of unit 5.

To verify the mathematical formulations for the customer side (Eqs. (27)-(29)), two aggregated industrial consumers are assumed. The load data for both aggregated customer groups are similar to those given in Tables IV and V, the only difference is in the number of customers within each aggregated group. It is assumed that both aggregated industrial customer groups consist of 30 and 20 identical customers, respectively, and there is a regulator that can schedule these loads.

The solution methodology employed is similar to the first example test system. AIMMS is again used to solve both optimization problems. In this work, after the third round of interactive control, convergence was achieved. Figure 12 shows the initial system load and the final

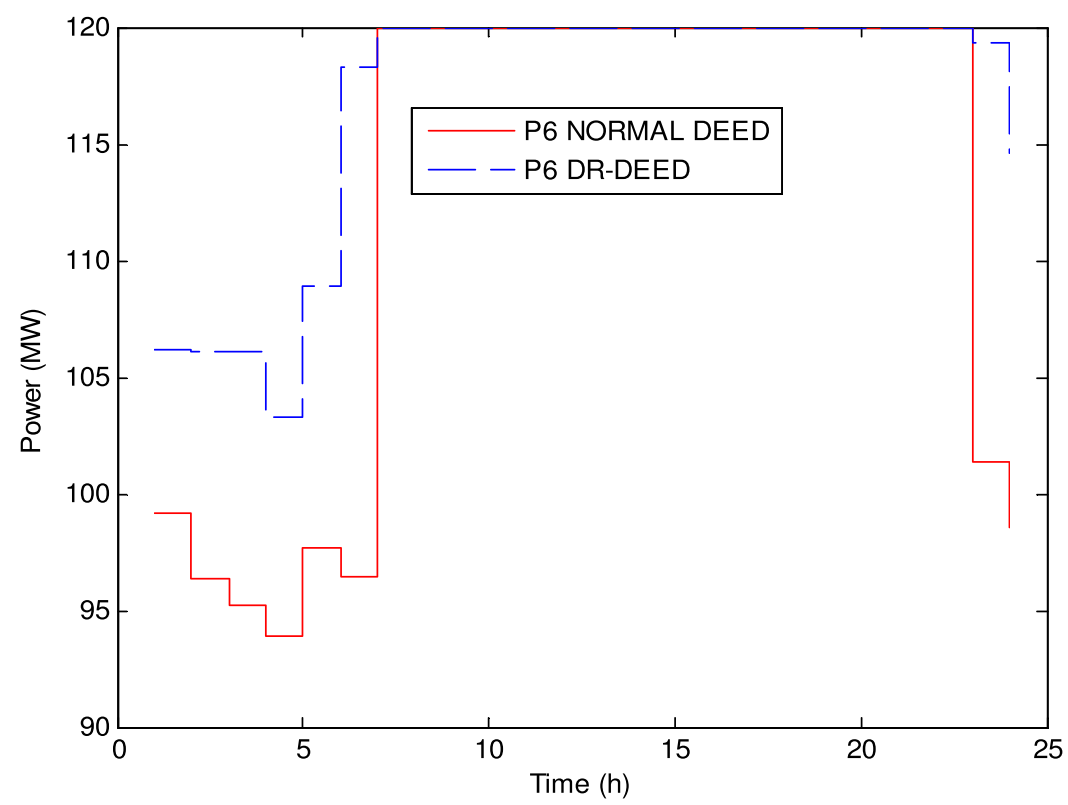

FIG. 11. Generation output of unit 6 . 
TABLE IV. Optimal DEED cost, emission, and loss with various weighting factor values (test system 1). Bold text indicates the base case when equal preference is given to both objective functions.

\begin{tabular}{lcccccc}
\hline \hline & $\begin{array}{c}\text { Cost } \\
(\mathrm{DEED})(\mathrm{R})\end{array}$ & $\begin{array}{c}\text { Emissions } \\
(\mathrm{DEED})(\mathrm{lb})\end{array}$ & $\begin{array}{c}\text { Loss } \\
(\mathrm{DEED})(\mathrm{MW})\end{array}$ & $\begin{array}{c}\text { Cost } \\
\text { (DR-DEED) (R) }\end{array}$ & $\begin{array}{c}\text { Emissions } \\
\text { (DR-DEED) }(\mathrm{lb})\end{array}$ & $\begin{array}{c}\text { Loss (DR-DEED) } \\
(\mathrm{MW})\end{array}$ \\
\hline$w=0$ & 342946 & 30995 & 339 & 341581.0874 & 29281.74727 & 317.6168695 \\
$w=0.1$ & 342348 & 31034 & 342 & 340878.0754 & 29331.2034 & 321.7372105 \\
$w=0.2$ & 341503 & 31200 & 345 & 340245.3722 & 29463.33555 & 326.0064279 \\
$w=0.3$ & 340673 & 31501 & 349 & 339449.6479 & 29766.06765 & 331.1171942 \\
$w=0.4$ & 339927 & 31950 & 354 & 338657.9488 & 30249.67842 & 337.5981386 \\
$w=\mathbf{0 . 5}$ & $\mathbf{3 3 9 1 0 5}$ & $\mathbf{3 2 6 9 6}$ & $\mathbf{3 6 0}$ & $\mathbf{3 3 7 8 7 3 . 1 1 0 4}$ & $\mathbf{3 0 9 9 2 . 7 9 3 2 9}$ & $\mathbf{3 4 5 . 0 2 2 3 5 0 6}$ \\
$w=0.6$ & 338450 & 33612 & 366 & 337123.8609 & 32055.83877 & 353.4399111 \\
$w=0.7$ & 337935 & 34751 & 373 & 336525.8092 & 33411.16032 & 362.6221717 \\
$w=0.8$ & 337613 & 36033 & 381 & 336136.5383 & 34970.12488 & 372.3296417 \\
$w=0.9$ & 337502 & 37236 & 389 & 335980.103 & 36580.41833 & 382.1216955 \\
$w=1$ & 337541 & 38475 & 397 & 336021.406 & 38078.86841 & 391.454633 \\
\hline \hline
\end{tabular}

TABLE V. Optimal load scheduling model solution for customer in the first group (test system 1).

\begin{tabular}{llc}
\hline \hline Loads & Time slots (h) \\
\hline 1 & $7-11,13-14,16,18-21$ \\
2 & $7-11,14,16-20,22$ \\
3 & $1-24$ \\
4 & $1-24$ \\
5 & $5-6,21-23$ \\
6 & $1-3,22$ \\
\hline \hline
\end{tabular}

TABLE VI. Optimal load scheduling model solution for customer in the second group (test system 1).

\begin{tabular}{llc}
\hline \hline Loads & Time slots (h) \\
\hline 1 & $1-4,11-15,17,23-24$ \\
2 & $6-10,13,16,18-22$ \\
3 & $7-10,12,15-20$ \\
4 & $1-24$ \\
5 & $5-6,21-22,24$ \\
6 & $5-6,21-22$ \\
\hline \hline
\end{tabular}

optimal converged load. It shows that there is a reduction in peak demand and also a shifting of load from peak periods. Figure 13 shows the initial price and the final utility price. As in Figure 5, it is obvious that there is a price reduction in standard and off-peak periods and an increase in peak periods and these price movements have the intended effect on the energy consumption. Figures 14 and 15 show the optimal power generated for generators 1 and 2 under initial system load (normal DEED) and optimal converged load (DR-DEED), respectively. Due to the increase and reduction in load, there is a corresponding increase and reduction in power supplied from the generators. Table VII shows the results of varying the weighting factors on the fuel costs, emissions, and power loss under both DEED and DR-DEED for the second test system. The final customer optimal scheduling solution is shown in Tables VIII and IX for customers in the first and second groups, respectively. 


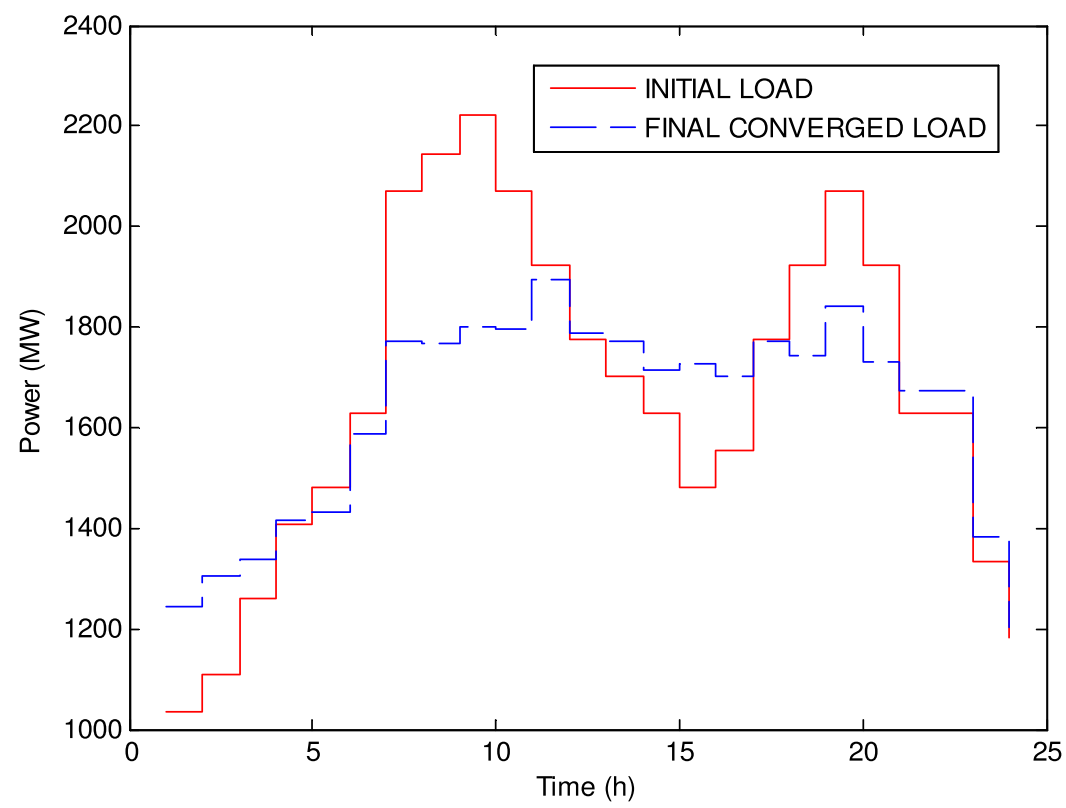

FIG. 12. Initial load and final converged load (test system 2).

\section{Discussion of results}

In summary, a concise and sequential description of the steps followed in this paper is described using the first test system below:

Step 1: Obtain initial load profile and initial pricing scheme (initial load in Figure 2 and initial price in Figure 3, respectively).

Step 2: The utility performs DR-DEED optimization (using Eqs. (20)-(26)) and obtains the utility forecast load and price (first utility forecast load in Figure 2 and utility first price in Figure 3, respectively).

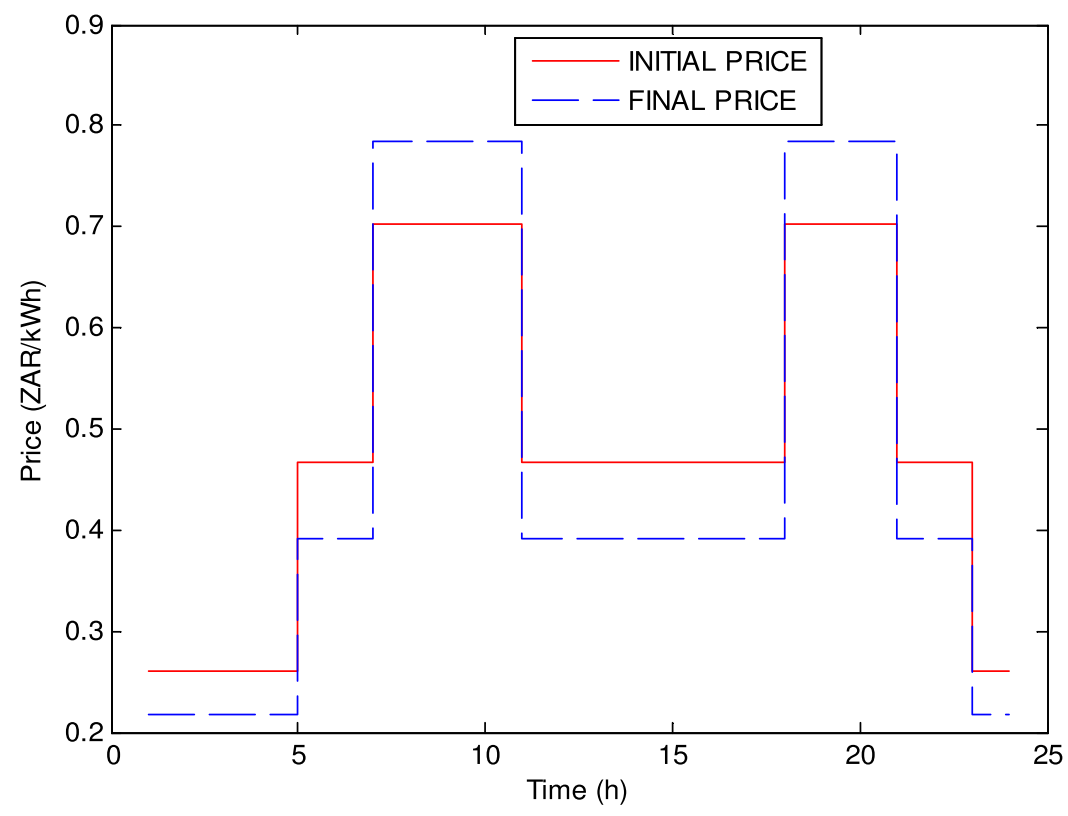

FIG. 13. Initial price and final price (test system 2). 


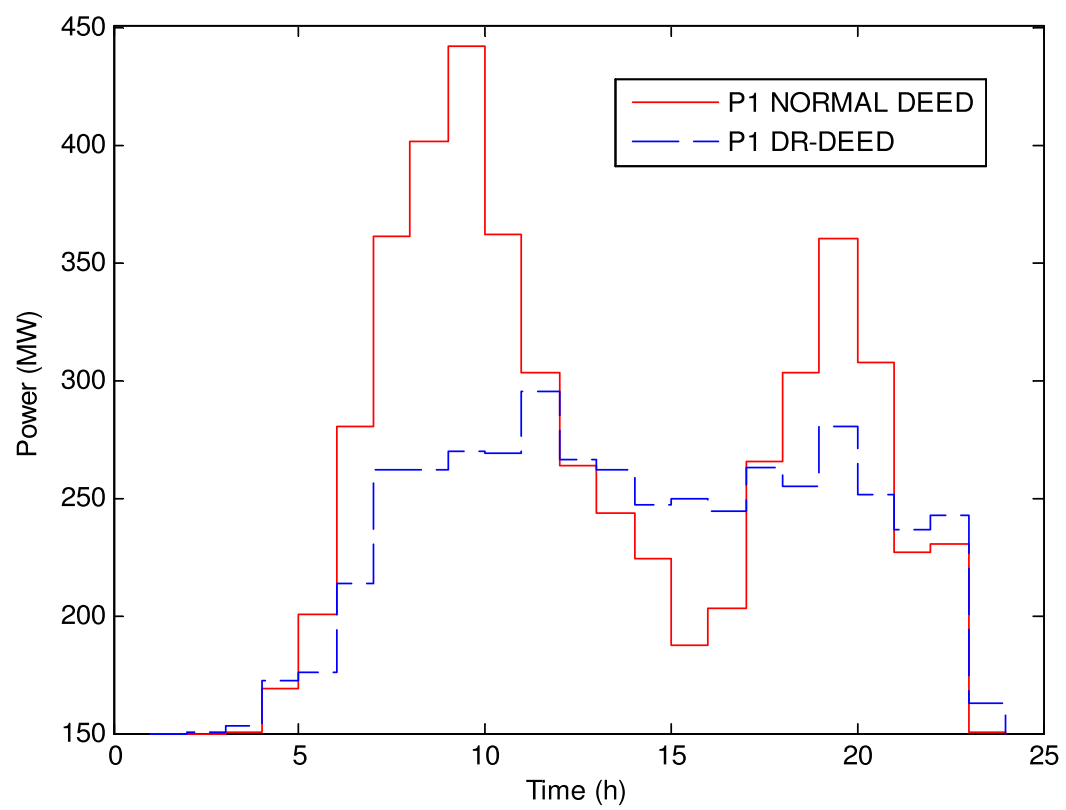

FIG. 14. Generation output of unit 1 (test system 2).

Step 3: In light of the utility's given price, the customers schedule their loads (using Eqs. (27)-(29)) and return the information back to the utility (first customer load in Figure 2).

Step 4: The utility revises the PEM and again performs DR-DEED optimization (using Eqs. (20)-(26)) and again obtains the utility price (utility second price in Figure 3).

Step 5: The customers again schedule their loads (using Eqs. (27)-(29)) in light of the new price and returns the information back to the utility (second customer load in Figure 2).

This interactive scheme continues until convergence is reached. In test system 1, this happens when the second customer load equals the first customer load (see second customer load and first customer load in Figure 2). In this context, we define convergence as when the utility's

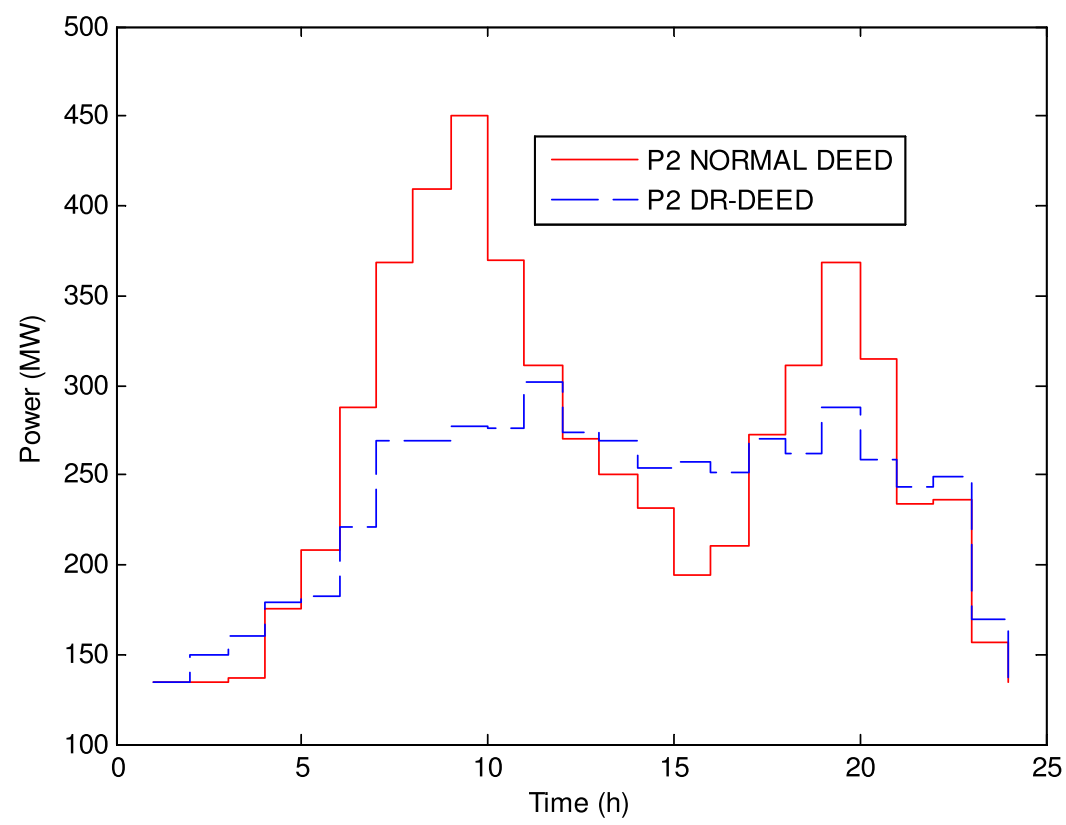

FIG. 15. Generation output of unit 2 (test system 2). 
TABLE VII. Optimal DEED cost, emission, and loss with various weighting factor values (test system 2). Bold text indicates the base case when equal preference is given to both objective functions.

\begin{tabular}{lcccccc}
\hline \hline & $\begin{array}{c}\text { Cost } \\
\text { (DEED) (R) }\end{array}$ & $\begin{array}{c}\text { Emissions } \\
\text { (DEED) (lb) }\end{array}$ & $\begin{array}{c}\text { Loss } \\
\text { (DEED) (MW) }\end{array}$ & $\begin{array}{c}\text { Cost } \\
\text { (DR-DEED) (R) }\end{array}$ & $\begin{array}{c}\text { Emissions } \\
\text { (DR-DEED) (lb) }\end{array}$ & $\begin{array}{c}\text { Loss } \\
\text { (DR-DEED) (MW) }\end{array}$ \\
\hline$w=0$ & 1054224 & 248251 & 1322 & 1032488 & 201833.378 & 1208.975575 \\
$w=0.1$ & 1053155 & 248335 & 1322 & 1032317.207 & 201849.9257 & 1209.337727 \\
$w=0.2$ & 1051556 & 248616 & 1322 & 1031558.711 & 201990.8156 & 1209.8147 \\
$w=0.3$ & 1051049 & 248799 & 1322 & 1031149.414 & 202145.7047 & 1210.285814 \\
$w=0.4$ & 1050295 & 249232 & 1323 & 1030376.402 & 202601.3071 & 1210.981333 \\
$w=\mathbf{0 . 5}$ & $\mathbf{1 0 4 9 4 1 9}$ & $\mathbf{2 4 9 9 9 2}$ & $\mathbf{1 3 2 4}$ & $\mathbf{1 0 2 8 9 6 2 . 7 9 3}$ & $\mathbf{2 0 3 8 2 7 . 1 3 3 5}$ & $\mathbf{1 2 1 2 . 2 5 3 4 2}$ \\
$w=0.6$ & 1047376 & 252671 & 1326 & 1025657.354 & 208270.9772 & 1215.233878 \\
$w=0.7$ & 1043923 & 259564 & 1330 & 1020300.863 & 218584.6925 & 1221.682126 \\
$w=0.8$ & 1039460 & 274423 & 1343 & 1015861.032 & 233260.7197 & 1233.855972 \\
$w=0.9$ & 1034599 & 308177 & 1374 & 1010121.273 & 273874.5636 & 1271.854093 \\
$w=1$ & 1032513 & 378260 & 1424 & 1006570.04 & 385080.8014 & 1353.525977 \\
\hline \hline
\end{tabular}

TABLE VIII. Optimal load scheduling model solution for first group of customers (test system 2).

\begin{tabular}{lcc}
\hline \hline Loads & Time slots (h) \\
\hline 1 & $7-10,12-16,18-20$ \\
2 & $7-8,10-18,20$ \\
3 & $1-24$ \\
4 & $1-24$ \\
5 & $1,3,5,21,24$ \\
6 & $1-2,4,21$ \\
\hline \hline
\end{tabular}

TABLE IX. Optimal load scheduling model solution for second group of customers (test system 2).

\begin{tabular}{llc}
\hline \hline Loads & Time slots (h) \\
\hline 1 & $4,6,9,11-13,16-17,19,21-23$ \\
2 & $3,7-8,10-15,18,20,22$ \\
3 & $7-11,14-15,17-20$ \\
4 & $1-24$ \\
5 & $2,5-6,21-22$ \\
6 & $2,5-6,22$ \\
\hline \hline
\end{tabular}

given price does not cause a change in the customers prior load schedule, thus obtaining an electricity price and demand mutually acceptable to the utility and customers whilst simultaneously reducing energy levels.

The DR program helps to reduce power system congestion, especially around peak times. It also shifts the load to the off peak and standard periods. Most of the generators produce more off peak/standard periods in order to reduce power production in peak periods. From the numerical simulations at the customer side, the model returns the optimal time slots to use the devices/appliances. The flexibility of the appliances is dictated by the peculiar needs of the customer and these determine the constraints of the mathematical model. The advantage of the interactive control strategy is the information flow is uni-directional, and the energy levels are 
obtained that provide power system relief and are acceptable to the utility and consumers. The model can be easily extended to accommodate a wider variety of consumers.

Figures 4 and 12 show the initial load and final converged load for test system 1 and test system 2, respectively. For both test systems, the benefit of DR is evident as there is load shifting and peak load reduction. This would have a commensurate effect on fuel costs reduction, emissions reduction, and power losses. Figures 5 and 13 show the initial price and final price for test system 1 and test system 2, respectively. Comparing the load graphs and the price graphs, it becomes clear that the interactive control process causes a TOU price increase in peak periods, which then has the intended effect of reducing customer loads in these periods. In standard and off-peak periods, there is a price reduction which incentivises customers to shift their load to these periods. Thus, customers shift their loads from periods when the power system is stressed, and power supply is constrained (peak periods) to periods when the power system is relatively unstressed. The loads that are shifted are the flexible loads and the night time loads. The inflexible loads are not shifted, and they account for the residual loads during peak periods. Due to the power balance constraint, which seeks to ensure that the total power supplied from the generators equals the load demand, there is an increase in power supply during standard and off-peak periods and a reduction in power supply during peak periods (see Figures $6-11,14$, and 15). It is from this power reduction from the generators that the cost and emission savings occur. Also, the reduction in power system losses stem from this reduction. Tables $\mathrm{V}$ and VI show the hourly optimal scheduling results for the first and second group of customers in test system 1 in light of the final utility price. Similarly, Tables VIII and IX show the results for both customer groups in test system 2 .

Tables IV and VII give the optimal cost, emissions, and loss for DEED and DR-DEED for both example test systems. From both tables, the impact of DR on cost, emission, and losses can be clearly seen. DR brings a reduction in total demand, and hence, this brings about a corresponding decrease in costs, emissions, and losses. Both tables also show the variation of cost, emission, and losses when the weighting factor $(w)$ ranges from 0 to 1 . This analysis is important in multi-objective optimization problems with conflicting and competing objectives, to show how giving increased preference to one objective at the expense of the other influences the obtained results. In this case, it is observed that as $w$ increases, the cost decreases and the emission and losses increases. This means that as the weighting factor is increased (the importance of minimizing emissions is decreased, while the importance of minimizing costs increases), emissions and losses actually increase and costs decrease. This is consistent with results obtained from the literature ${ }^{29}$ and holds for both DEED and DR-DEED formulations.

\section{CONCLUSION}

This paper presents a modification of the DEED formulation with price based DR programs. The objective in the optimization problem is to minimize the fuel, emissions, and DR costs subject to the conventional DEED constraints and some extra constraints. Investigations with different price elasticity matrices were assumed, and the TOU tariffs were used as the initial prices, giving rise to a TOU based DR-DEED problem formulation. As an interactive control strategy is used in the work, two customer mathematical models are presented where the customer classifies their loads into flexible, inflexible, and night-time loads and optimizes their demand in light of the utility suggested demand and final price. The customer schedules their load in order to minimize their electricity consumption and hence their electricity costs. Obtained simulation results indicate that DR programs reduce the total load curve and peak demand. The DR program also shifts the loads from peak periods to standard and off-peak periods. This is due to the fact that TOU prices reduce in standard and off peak periods and increase in peak periods. This reduces the likelihood of a stressed power system and minimizes instances of brown outs and blackouts. The results obtained also show that due to the reduced demand there is a corresponding reduction in fuel costs, harmful emissions, and power loss in both test systems considered. In essence, the results show that TOU-DR programs can bring about a reduction and shifting of load demand with customers who are actively interacting 
participants and who engage with the utility to reduce system demand. The interactive process employed also enabled the utility obtain optimal TOU prices acceptable to both utility and consumers alike. Future work will consider DR-DEED for a power system powered by combined heat and power $(\mathrm{CHP})$ generators.

APPENDIX: POWER SYSTEM DATA

TABLE X. Data of the 6-unit system.

\begin{tabular}{ccccccccccc}
\hline \hline & $\begin{array}{c}a_{i} \\
\mathrm{R} / \mathrm{h})\end{array}$ & $\begin{array}{c}b_{i} \\
(\mathrm{R} / \mathrm{MW} \mathrm{h})\end{array}$ & $\begin{array}{c}c_{i} \\
\left(\mathrm{R} / \mathrm{MW}^{2} \mathrm{~h}\right)\end{array}$ & $\begin{array}{c}e_{i} \\
(\mathrm{lb} / \mathrm{h})\end{array}$ & $\begin{array}{c}f_{i} \\
(\mathrm{lb} / \mathrm{MW} \mathrm{h})\end{array}$ & $\begin{array}{c}g_{i} \\
\left(\mathrm{lb} / \mathrm{MW}^{2} \mathrm{~h}\right)\end{array}$ & $\begin{array}{c}P_{i, \min } \\
(\mathrm{MW})\end{array}$ & $\begin{array}{c}P_{i, \max } \\
(\mathrm{MW})\end{array}$ & $\begin{array}{c}D R_{i} \\
(\mathrm{MW} / \mathrm{h})\end{array}$ & $\begin{array}{c}U \\
U R_{i} \\
(\mathrm{MW} / \mathrm{h})\end{array}$ \\
\hline 1 & 240 & 7 & 0.007 & 13.8593 & 0.32767 & 0.00419 & 100 & 500 & 120 & 80 \\
2 & 200 & 10 & 0.0095 & 13.8593 & 0.32767 & 0.00419 & 50 & 200 & 90 & 50 \\
3 & 220 & 8.5 & 0.009 & 40.2669 & -0.54551 & 0.00683 & 80 & 300 & 100 & 65 \\
4 & 200 & 11 & 0.009 & 40.2669 & -0.54551 & 0.00683 & 50 & 150 & 90 & 50 \\
5 & 220 & 10.5 & 0.008 & 42.8955 & -0.51116 & 0.00461 & 50 & 200 & 90 & 50 \\
6 & 190 & 12 & 0.0075 & 42.8955 & -0.51116 & 0.00461 & 50 & 120 & 90 & 50 \\
\hline \hline
\end{tabular}

TABLE XI. Initial TOU prices and total demand (test system 1).

\begin{tabular}{lcc}
\hline \hline Time $(\mathrm{h})$ & TOU prices $(\mathrm{R} / \mathrm{kW})$ & Total demand $(\mathrm{MW})$ \\
\hline 1 & 0.2595 & 963 \\
2 & 0.2595 & 948 \\
3 & 0.2595 & 942 \\
4 & 0.2595 & 935 \\
5 & 0.4669 & 955 \\
6 & 0.4669 & 963 \\
7 & 0.7021 & 1263 \\
8 & 0.7021 & 1380 \\
9 & 0.7021 & 1360 \\
10 & 0.7021 & 1210 \\
11 & 0.4669 & 1165 \\
12 & 0.4669 & 1143 \\
13 & 0.4669 & 1110 \\
14 & 0.4669 & 1117 \\
16 & 0.4669 & 1170 \\
17 & 0.4669 & 1150 \\
18 & 0.4669 & 1221 \\
19 & 0.7021 & 1420 \\
20 & 0.7021 & 1445 \\
21 & 0.7021 & 1430 \\
22 & 0.4669 & 1238 \\
23 & 0.4669 & 1159 \\
24 & 0.2595 & 975 \\
\hline \hline
\end{tabular}


TABLE XII. Data of the ten-unit system.

\begin{tabular}{ccccccccccc}
\hline \hline & $\begin{array}{c}a_{i} \\
\mathrm{i} / \mathrm{h})\end{array}$ & $\begin{array}{c}b_{i} \\
(\mathrm{R} / \mathrm{MW} \mathrm{h})\end{array}$ & $\begin{array}{c}c_{i} \\
\left(\mathrm{R} / \mathrm{MW}^{2} \mathrm{~h}\right)\end{array}$ & $\begin{array}{c}e_{i} \\
(\mathrm{lb} / \mathrm{h})\end{array}$ & $\begin{array}{c}f_{i} \\
(\mathrm{lb} / \mathrm{MW} \mathrm{h})\end{array}$ & $\begin{array}{c}g_{i} \\
\left(\mathrm{lb} / \mathrm{MW}^{2} \mathrm{~h}\right)\end{array}$ & $\begin{array}{c}P_{i, \min } \\
(\mathrm{MW})\end{array}$ & $\begin{array}{c}P_{i, \max } \\
(\mathrm{MW})\end{array}$ & $\begin{array}{c}D R_{i} \\
(\mathrm{MW} / \mathrm{h})\end{array}$ & $\begin{array}{c}U R_{i} \\
(\mathrm{MW} / \mathrm{h})\end{array}$ \\
\hline 1 & 958.2 & 21.6 & 0.00043 & 360.0012 & -3.9864 & 0.04702 & 150 & 470 & 80 & 80 \\
2 & 1313.6 & 21.05 & 0.00063 & 350.0056 & -3.9524 & 0.04652 & 135 & 460 & 80 & 80 \\
3 & 604.97 & 20.81 & 0.00039 & 330.0056 & -3.9023 & 0.04652 & 73 & 340 & 80 & 80 \\
4 & 471.6 & 23.9 & 0.0007 & 330.0056 & -3.9023 & 0.04652 & 60 & 300 & 50 & 50 \\
5 & 480.29 & 21.62 & 0.00079 & 13.8593 & 0.3277 & 0.0042 & 73 & 243 & 50 & 50 \\
6 & 601.75 & 17.87 & 0.00056 & 13.8593 & 0.3277 & 0.0042 & 57 & 160 & 50 & 50 \\
7 & 502.7 & 16.51 & 0.00211 & 40.2669 & -0.5455 & 0.0068 & 20 & 130 & 30 & 30 \\
8 & 639.4 & 23.23 & 0.0048 & 40.2669 & -0.5455 & 0.0068 & 47 & 120 & 30 & 30 \\
9 & 455.6 & 19.58 & 0.10908 & 42.8955 & -0.5112 & 0.0046 & 20 & 80 & 30 & 30 \\
10 & 692.4 & 22.54 & 0.00951 & 42.8955 & -0.5112 & 0.0046 & 55 & 55 & 30 & 30 \\
\hline \hline
\end{tabular}

TABLE XIII. Initial TOU prices and total demand (test system 2).

\begin{tabular}{lcc}
\hline \hline Time $(\mathrm{h})$ & TOU prices $(\mathrm{R} / \mathrm{kW})$ & Total demand $(\mathrm{MW})$ \\
\hline 1 & 0.2595 & 1036 \\
2 & 0.2595 & 1110 \\
3 & 0.2595 & 1258 \\
4 & 0.2595 & 1406 \\
5 & 0.4669 & 1480 \\
6 & 0.4669 & 1628 \\
7 & 0.7021 & 2072 \\
8 & 0.7021 & 2146 \\
9 & 0.7021 & 2220 \\
10 & 0.7021 & 2072 \\
11 & 0.4669 & 1924 \\
12 & 0.4669 & 1776 \\
13 & 0.4669 & 1702 \\
14 & 0.4669 & 1628 \\
16 & 0.4669 & 1480 \\
17 & 0.4669 & 1554 \\
18 & 0.4669 & 1776 \\
19 & 0.7021 & 1924 \\
20 & 0.7021 & 2072 \\
21 & 0.7021 & 1924 \\
22 & 0.4669 & 1628 \\
23 & 0.4669 & 1628 \\
24 & 0.2595 & 1332 \\
\hline \hline
\end{tabular}

${ }^{1}$ P. Attaviriyanupap, H. Kita, E. Tanaka, and J. Hasegawa, IEEE Trans. Power Syst. 17, 411 (2002).

${ }^{2}$ Z. L. Gaing, "Constrained dynamic economic dispatch solution using particle swarm optimization," in Proceedings of the IEEE Power Engineering Society General Meeting (2004), pp. 153-158.

${ }^{3}$ X. S. Han and H. B. Gooi, Int. J. Electr. Power Energy Syst. 29, 113 (2007).

${ }^{4}$ C. K. Panigrahi, P. K. Chattopadhyay, and R. Chakrabarti, Int. J. Autom. Control 1, 182 (2007).

${ }^{5}$ X. Xia and A. M. Elaiw, Electr. Power Syst. Res. 80, 975 (2010).

${ }^{6}$ X. Xia, J. Zhang, and A. M. Elaiw, Control Eng. Pract. 19, 638 (2011).

${ }^{7}$ J. H. Talaq, F. El-Hawary, and M. E. El-Hawary, IEEE Trans. Power Syst. 9, 1508 (1994).

${ }^{8}$ M. Basu, Int. J. Electr. Power Energy Syst. 30, 140 (2008). 
${ }^{9}$ M. Basu, Electr. Power Compon. Syst. 34, 1015 (2006)

${ }^{10}$ M. Basu, Int. J. Emerging Electr. Power Syst. 8, 1 (2007).

${ }^{11}$ Y. H. Song and I. K. Yu, Electr. Power Syst. Res. 43, 53 (1997).

${ }^{12}$ A. M. Elaiw, X. Xia, and A. M. Shehata, Electr. Power Syst. Res. 84, 31 (2012).

${ }^{13}$ I. J. Raglend and N. P. Padhy, "Solutions to practical unit commitment problems with operational, power flow and environmental constraints," in Proceedings of the Power Engineering Society General Meeting, Montreal, Canada, 18-22, June 2006.

${ }^{14}$ B. Bahmanifirouzi, E. Farjah, and T. Niknam, J. Renewable Sustainable Energy 4, 023105 (2012).

${ }^{15}$ M. Fahrioglu and N. I. Nwulu, J. Electr. Rev. 88, 239 (2012).

${ }^{16} \mathrm{~F}$. Saffre and R. Gedge, "Demand side management for the smart grid," in Proceedings of the IEEE/IFIP Network Operations and Management Symposium, Osaka, Japan, April 2010.

${ }^{17}$ W. Gellings, Proc. IEEE 73, 1468 (1985).

${ }^{18}$ Department of Energy, U. S. Benefits of demand response in electricity markets and recommendations for achieving them, 2006.

${ }^{19}$ O. Sezgen, C. A. Goldman, and P. Krishnarao, Energy 32, 108 (2007).

${ }^{20}$ N. I. Nwulu and M. Fahrioglu, Neural Comput. Appl. 22, 1115 (2013).

${ }^{21}$ N. I. Nwulu and M. Fahrioglu, A neural network model for optimal demand management contract design, in Proceedings of the 10th Environmental \& Electrical Engineering Conference, Rome, Italy, 8-11 May 2011.

${ }^{22}$ N. I. Nwulu and M. Fahrioglu, Int. Rev. Modell. Simul. 4, 106 (2011).

${ }^{23}$ F. C. Schweppe, M. C. Caramanis, R. D. Tabors, and R. E. Bohn, Spot Pricing of Electricity (Kluwer Academic Publishers, Boston, 1987).

${ }^{24}$ D. S. Kirschen, G. Strbac, P. Cumperayot, and D. Mendes, IEEE Trans. Power Syst. 15, 612 (2000).

${ }^{25} \mathrm{See} \mathrm{http://www.eskom.co.za/c/article/145/tariffs/} \mathrm{for} \mathrm{Eskom} \mathrm{Tariffs} \mathrm{and} \mathrm{Charges,} \mathrm{Last} \mathrm{accessed} 15$ October 2014.

${ }^{26} \mathrm{E}$. Malatji, J. Zhang, and X. Xia, Energy Build. 61, 81 (2013).

${ }^{27}$ X. Xia, J. Zhang, and W. Cass, J. Energy S. Afr. 23, 23 (2012).

${ }_{28}^{28}$ J. Bisschop and M. Roelofs, AIMMS Language Reference, Version 3.12 (Paragon Decision Technology, Haarlem, 2011).

${ }^{29}$ A. M. Elaiw, X. Xia, and A. M. Shehata, See http://dx.doi.org/10.1155/2013/906958 for Mathematical Problems in Engineering, 2013.

${ }^{30}$ F. H. Magnago, J. Alemany, and J. Lin, Int. J. Electr. Power Energy Syst. 68, 142 (2015).

${ }^{31}$ N. I. Nwulu and X. Xia, Energy Convers. Manage. 89, 963 (2015).

${ }^{32}$ K. Geetha, V. Sharmila Deve, and K. Keerthivasan, Int. J. Electr. Power Energy Syst. 68, 222 (2015).

${ }^{33}$ H. M. Dubey, M. Pandit, and B. K. Panigrahi, Renewable Energy 83, 188 (2015).

${ }^{34}$ X. Ran, S. Miao, Z. Jiang, and H. Xu, Int. J. Electr. Power Energy Syst. 73, 23 (2015).

${ }^{35}$ Y. Zhu, J. Wang, and B. Qu, Int. J. Electr. Power Energy Syst. 63, 434 (2015).

${ }^{36}$ M. J. Morshed and A. Asgharpour, Energy Conserv. Manage. 84, 30 (2014).

${ }^{37}$ R. Azizipanah-Abarghooee, T. Niknam, M. A. Bina, and M. Zare, Energy 79, 50 (2015).

${ }^{38}$ Y. Z. Li, Q. H. Wu, M. S. Li, and J. P. Zhan, Energy 72, 510 (2014). 